\title{
Participation of Firms in the Skills Develop- ment Levy System
}

\section{Gregory John Lee}

School of Economic and Business Sciences, University of the Witwatersrand

\section{ABSTRACT}

Skills development levies are increasingly being utilised to increase enterprise provided training in developing economies. South Africa is one such example. The impact of such incentive systems on the bottom-line of firms is a vital consideration in such programs. Particularly important are the economic conditions under which the incentive will stimulate participation by organisations. The transaction costs of participation must be taken into account: while a levy-grant system clearly creates a prima-facie incentive, it may be prohibitively expensive for some firms to enter the grant disbursement systems. Accordingly, through a simple model of the incentives for firms, the participation level of the firm under various types of levy systems is assessed. Non-monetary considerations are also considered. The implications for participation by firms, along with managerial and policy implications, are discussed.

JEL J31, 38, M53

\section{INTRODUCTION}

The competitiveness of nations has long been predicated upon levels of human capital, notably skills. Accordingly, most governments seek to regulate education and training systems at multiple levels. One intervention frequently utilised as an incentive for firms to undertake employer provided training (EPT) is levies on payroll (Dougherty \& Tan, 1997; Middleton, Ziderman \& Van Adams, 1993; Whalley \& Ziderman, 1990; Ziderman, 1996 \& 2001).

Such levy-based EPT incentives have different possible structures (Glasskov, 1994). The most common is a levy-grant system (Middleton et al, 1993; Whalley \& Ziderman, 1990; Ziderman, 1996), in terms of which firms are levied a certain amount and can claim back portions of the levy for undertaking prescribed activities. This is broadly speaking the system recently adopted by the South African government in terms of the Skills Development Act 97 of 1998 and the Skills Development Levies Act 9 of 1999. 
In the South African levy-grant system firms are levied 1.5 per cent of payroll at the beginning of the annual period. The firm can then reclaim portions of the levy if it proves its participation in the prescribed activities, via reports submitted to its Sectoral Education and Training Authority, or 'SETA'. In short, the grant amounts are as follows:

- $\quad$ Grant A (workplace skills plan): A lump-sum 15 per cent of the levy can be reclaimed by the firm if they register a skills development facilitator and workplace skills plan on a yearly basis. This is done earlier in each annual period than the other grants.

- $\quad$ Grant B (workplace skills implementation): The second grant is worth up to 45 per cent of the levy. It is given for actual training done by the firm in line with its previously registered workplace skills plan. In other words, Grant B can only be claimed sequentially, after Grant A has been claimed. This is crucial for the modelling later.

- Grant C (ad hoc sector specific training): A further 10 per cent of the levy can be made available as ad hoc grants for participation in sectoral specific training, as defined by the SETA. These are not dependent upon Grant A.

As can be seen, therefore, the firm can claim back up to 70 per cent of the total levy if it participates to the maximum extent possible. Figure 1 provides a précis.

The prescribed activities required for the firm to claim back grants (i.e. the workplace skills facilitation, plan, and training implementation) are the variables of real interest to policy makers. This is notwithstanding the other spin-offs of the levy, such as the 20 per cent of the levy given to the National Skills Authority to do general skills training or the other externalities (Lee, 2003). Ultimately, the fundamental aim of the system is to stimulate new training activities (Lee, 2003). In that regard, it is real increases in levels of these activities that is of primary concern. Of these, too, the ultimate issue is increases in actual training programs: no number of facilitators or plans will suffice if there is not an increase in actual skills transfer.

However, from the perspective of organisational managers, participation in the prescribed grant activities, especially increases in these activities, is hardly certain. With regards to grant reclamation, an organisation may find it more efficacious simply to incur the levy and avoid the prohibitive indirect costs of transacting with what is often a complex bureaucratic system (Dougherty \& Tan, 1997). Indeed, lack of interest by organisations in reclaiming their full grants has been reported (e.g. Grawitzky, 2002). Should this be the case, any aim of the levy system to increase EPT is undermined. 


\section{Figure 1 Schematic representation of South African skills levy system}

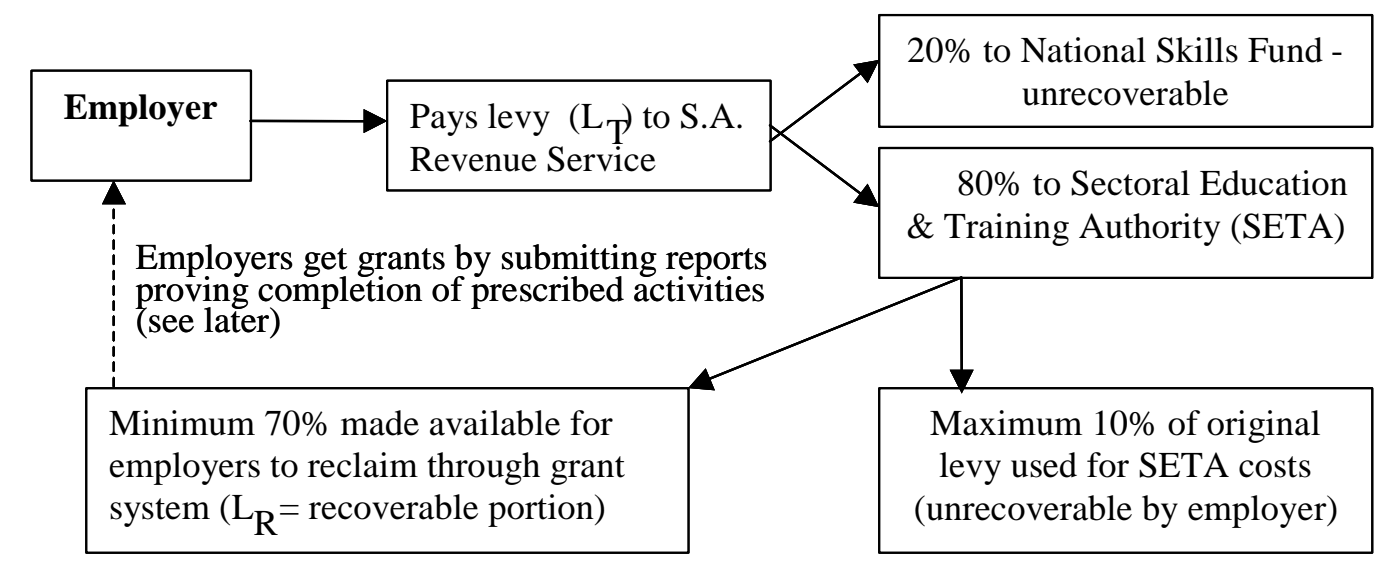

Furthermore, it is hard to distinguish between the registration of training activities that already existed before the levy system was introduced, and new activities genuinely stimulated by the levy system (the latter being the more desired). In this vein, this article will primarily attempt to deal with why firms might choose to participate to any given level in the grant reclamation system and/or the underlying training-related activities for which the grants are given.

A simple model of the participation decision of a rational organisation in the prescribed activities of a levy-grant incentive will accordingly be developed. The impediments in the system to the full participation of firms are included and discussed. Finally, implications, especially for policy, are suggested.

\section{VARIABLES OF IMPORTANCE IN FIRM PARTICIPATION}

What are the variables of interest that the firm will take into consideration when deciding whether or not to participate in the activities required to claim grants? Logically, the possible variables and issues could include 1) whether the activity was profitable for the firm before the introduction of the levy, 2) the levy amount itself, 3) the grant amounts, 4) the transaction costs of dealing with the grant reclamation system (Lee, 2001). These will be dealt with below, although it is shown that the levy does not in fact play a role. The role of each variable in eliciting participation will be assessed below, as a prelude to the building of a model. 


\subsection{The 'natural' profitability of the activities}

As seen above, the levy-grant system is designed to alter the cost-benefit landscape for the firm regarding several training activities. A fundamental issue is the extent to which these activities were seen to be profitable for the firm in the first place, i.e. before the introduction of the levy. These will be referred to as the 'natural' profitability considerations. The natural benefits will largely be the effect of the training activity on employee productivity. The natural costs will include the usual training-related direct and opportunity costs (Lee, 2001).

A crucial assumption made here is that if the natural value of any of the relevant training activities is seen to outweigh the cost, then the firm will presumably already have been doing the activity in the absence of the levy-grant incentive. If the reverse is true, the firm will not be doing the activity. This is, of course, a simplification of reality, but a common and useful one.

As stated above, the major aim of the levy-grant system is presumably to increase the levels of new training activities. Therefore, in cases where the natural productivity already leads the firm to do the activities, the grant system is fairly irrelevant (except inasmuch as it encourages quality control etc.) Rather, the grant system is primarily concerned with the case where managers perceive (rightly or wrongly) that the natural costs outweigh the benefits. This natural shortfall is what the grant system needs to target in order for the firm to become incentivised. Accordingly, the extent or magnitude of the natural 'loss' is the crucial base variable in the extent to which the levy-grant system will be able to motivate firms to actually engage in new training activities.

\subsection{The recoverable portion of the levy}

Notwithstanding its magnitude, if it is seen as separate from the grants then the levy (both its recoverable and unrecoverable portions) is an irrelevant decision theoretic variable in the firm's decision about whether to claim back grants or not. The unrecoverable 30 per cent of the levy is lost regardless of any action by the firm. The recoverable 70 per cent portion becomes relevant only when seen as reclaimable grants, which will be dealt with below (i.e. it is only the promise of getting it back as grants that will stimulate the firm to action).

Furthermore, evidence and theory suggest that the financial burden of the levy is not borne by the firm (Lee, 2003; Whalley \& Ziderman, 1990). Instead there are indications that this cost is passed onto workers through lower wages and employment levels, and possibly higher product prices. Therefore, again, the levy is an irrelevant variable, in this case because the firm does not pay it. At worst the firm is left with zero monetary impact (the case where they pass the 
levy onto workers and take no further part in the system). At best other factors (the possibility of net profits from participating in the grant system) will lead to a separate decision to participate. In the latter case it was factors involved with the grant system that elicited participation, but nothing to do with the levy. We therefore move onto the grant system.

\subsection{The grants}

The grants can be expected to influence the firm's decision about participation in the system. The grants are designed to increase the utility of particular "strategic" training activities (i.e. largely the installation of a skills facilitator, skills plan, and implementation of that plan).

As mentioned above, the grants are designed to increase the utility of EPT activities especially in the case where they were not being done because natural costs outweighed perceived benefits. The greater the grant, the more companies on the margin will participate in the prescribed training activities.

However, even for a company on the margin of participation, the added incentive may not guarantee participation. Also central to the participation decision will be the transaction costs of entering into the system, as explicated next.

\subsection{The transaction costs of participation}

The impact of the levy-grant system on the firm's decision to participate in the prescribed activities is not limited to the addition of the grant incentive to the 'natural' utility variables. Any organisation undertaking the grant reclamation tasks will also incur indirect transaction costs from the administration and other costs involved. These indirect costs are the crucial link in understanding the chosen participation level of a rational firm, and especially possible reasons for non-participation.

The indirect costs of transacting with the skills development framework (SETA registration and the various grant actions) probably include the following:

- $\quad$ Firstly, SETA registration and membership incurs certain participation and opportunity costs, such as any administration involved;

- Secondly, the registration and activities of the skills development facilitator (the first Grant A activity) will also incur transaction costs, as will the drawing up of a skills plan. Although these activities result in a grant return, they incur potentially large costs. The employee registered as facilitator will lose productive time doing skills development work, if 
engaged elsewhere (although see Dougherty \& Tan, 1997: 32) or may be a dedicated specialist who must be paid. Similarly, the drawing up of the plan will require organisational resources and time;

- Peculiar to each training program will also be costs associated with recording and submitting for Grant B or C consideration. Again, this will take up organisational time and resources;

- Finally, various miscellaneous transaction costs may arise, such as the calculation and payment of tax on grants.

Thus the decision to undertake the grant reclamation activities now consists of 1) the original 'natural' benefits and costs of training, 2) the potential for extra benefit from the grant, and 3) the negative transaction costs of complying with the grant reclamation bureaucracy. It should also be noted that certain positive externalities of training might be seen as a potential indirect benefit. This is discussed further at the end of the article.

Given the decision theoretic variables explicated above, the firm is faced with a decision as to whether to participate in the grant reimbursement activities, and if so to what extent. A framework for such a decision is accordingly examined next.

\section{THE FIRM'S PARTICIPATION DECISION}

As stated above, despite government's hopes that the skills development legislation will be an incentive to train, companies may choose not to participate in some or all of the activities. Instead, it is feasible that some organisations will pay the levy and have nothing more to do with the process (i.e. not participate in the SETA, not attempt to regain money from grants, and above all not change their training activities). Other companies may choose to participate in some of the initial activities, but not all. The aforementioned variables will drive these decisions, but how? Also, when is non-participation a real problem?

For the sake of initial clarity, the analysis will begin by assuming that there is only one training activity, incentivised via only one grant. In such a case, there are in fact two different types of possible participation. These are assessed next, albeit in this artificial setting for now.

\subsection{A grant stimulating registration of pre-existing training only}

The first type of participation involves companies that, because of the natural benefits, already do the training activity (e.g. they already have a facilitator). In 
other words, the grant system cannot stimulate the underlying training activity because it is already being done.

Since the activity is already in place, the firm needs make a decision only about whether or not to claim a grant for these pre-existing activities. In such a case, the grant amount merely needs to outweigh the transaction costs of the grant system for the company to reclaim the grant. Let the grant amount for activity $y$ be $G_{y}$ and the associated set of transaction costs be $T C_{y}$. Then $G_{y} \geq T C_{y}$ will assure that the firm registers the activity in order to claim the grant. The grant will add to the total utility of the activity, or at least not decrease utility.

Again, policy-makers wish for more than pre-existing training activities to be registered with the SETAs, without any stimulation of new activities. There are probably rationales for mere registration (better national and sectoral planning, perhaps higher quality, etc.) However the presumed first priority of the system is to stimulate new training activities. Therefore it is not sufficient that the grant merely outweigh the transaction costs. The stimulation of new activities is dealt with next.

\subsection{Stimulation of a new training activity}

The second situation is where the training activity $y$ is not currently being done by an organisation, presumably because its managers believe (rightly or wrongly) that the natural costs outweigh the benefits. Let the productivityrelated value of the activity be represented as $R_{y}$ and the associated direct and indirect costs be $C_{y}$. Presumably $C_{y}>R_{y}$ since the activity is not being done in the absence of a grant. Let the difference in these variables be a positive constant $k$ such that $C_{y}-R_{y}=k$.

In such a case, in order to stimulate the actual training activity the grant cannot merely be at least as big as the transaction costs. The net utility added by registering the activity for a grant would not only have to be zero or greater, but would have to stimulate the underlying activity itself. In order to do so, the following would generally be necessary:

$G_{y}-T C_{y} \geq C_{y}-R_{y} \quad$ i.e.
$G_{y}-T C_{y} \geq k$

Since it is precisely the stimulation of new training activities that is presumed to be the primary concern of the system, this is the situation that needs to be achieved with regards to any given activity or set thereof. 
Merely from this simple single-activity analysis, it is apparent that a core concern of the skills development system must be to ensure that:

- The transaction costs of participating in the system are at least no higher than the commensurate grants (which condition on its own will only stimulate registration of pre-existing training), and

- $\quad$ Preferably ensure that transaction costs are lower than the commensurate grants by the magnitude that the training activities are seen to be unprofitable by firms.

However this analysis gets more interesting, informative and complex when the number of possible training activities is widened from one to more than one, especially in a sequential sense. This is done next.

\subsection{Stimulating new training with multiple sequential activities}

In reality, one of the most important issues in the skills system is that of the sequential nature of the activities and grants. As shown in the introduction above, the activities for Grant A (i.e. facilitation and a workplace skills plan) must be completed and proved before Grant $\mathrm{B}$ (implementation of the workplace skills plan) can be claimed. (Grant $\mathrm{C}$ is independent, but of relatively small magnitude and hereafter not included in the analysis).

The second major grant activity, implementation of the workplace skills plan ("implementation"), is in reality probably composed of multiple incremental training programs and activities, adding up eventually to a grant amount anywhere between zero and 45 per cent of the levy. In other words, if organisations only implement a portion of their workplace skills plan up to the value of one third of the Grant $B$, then they will only receive one third. For now, however, let training implementation be seen as an all-or-nothing activity, i.e. the firm implements all of the workplace skills plan (qualifying them for the full Grant B worth 45 per cent of the levy) or none at all (qualifying them for no grant).

Then there are two training activities $y_{n}$ where $n=1,2$. Let $y_{1}$ be planning, and $y_{2}$ be implementation. In this case, both $y_{1}$ and $y_{2}$ are binary variables that can only take on the values of 0 (when the activity is not undertaken) or 1 (when the activity is undertaken and reported). Since the sequential nature of the real grant system means that Grant B cannot be claimed until Grant A is claimed, and using similar nomenclature to the prior example, the net utility from the grant reclamation activities can be expressed in a simple form as:

$y_{1}\left(G_{1}-T C_{1}\right)+y_{1} y_{2}\left(G_{2}-T C_{2}\right)$ 
The inclusion of $y_{1}$ in the second term shows that it must be done first, before $y_{2}$ can occur. Given the sequential nature of the grants there are three broad levels of participation. First is zero participation. Second would be participation in planning only, for 15 per cent of the levy return. Thirdly, companies could participate in planning and in addition implement some level of training (between zero implementation and up to the maximum 45 per cent of the levy grant). Again, a separate consideration is the independent Grant $\mathrm{C}$, but given its idiosyncratic nature and small value, this analysis will treat it as part of Grant B.

Recall that policy makers are most interested in the case where the natural productivity and cost variables of planning and especially training implementation are not leading to these activities being done (i.e. they want to stimulate new activities).

Let us first consider what it will take to move the firm from zero participation to participation in planning only. Since we can assume that the important cases are those where the firm is not naturally doing these things, we can again (as in 3.2. above and using similar notation) assume that $C_{1}>R_{1}$ and $C_{1}-R_{1}=k_{1}$ (where $k_{1}$ $>0$ ). As previously seen, participation in new planning is assured if

$$
G_{y 1}-T C_{y 1} \geq k_{1}
$$

i.e. if the net effect of the grant balances the natural loss. This is a sufficient condition for participation to this level, but not strictly necessary. This is because Grant A acts as a 'gateway' to the implementation grant, therefore planning may still make a loss for the firm if the later gains from implementation will balance the earlier loss. That is, planning may be seen as the cost portion of an investment that will bear returns later.

Assume therefore that training implementation makes a gain (on its own, independent of planning activities) of $G_{y 2}-T C_{y 2}-k_{2}$. It is actually not necessary to assume that $k_{2}>0$. Training may have been profitable prior to the introduction of the levy, in which case the grant makes it even more profitable if $G_{y 2}>T C_{y 2}$ or reduces the profitability if the reverse. Alternately the Grant B may have made implementation profitable where it was not so before.

Therefore the planning activities can still happen under a de facto loss so long as a 'profit' made later in the implementation activities balances this loss, i.e. if:

[a grant-adjusted gain from implementation] $\geq$ [a grant-adjusted loss from planning]

$G_{y 2}-T C_{y 2}-k_{2} \geq k_{1}-\left(G_{y 1}-T C_{y 1}\right)$

or

$G_{y 1}-T C_{y 1} \geq k_{1}-\left(G_{y 2}-T C_{y 2}-k_{2}\right)$ 
The above is, in fact, sufficient condition for total participation in all activities, i.e. given our assumption that implementation is either all or nothing the above will assure not only planning but implementation too. The second equation then is a condition for full participation, namely that the net effect of Grant A must exceed the 'natural' loss from planning less the net profitability of implementation.

This preliminary model shows several things of great importance to organisational participation:

1. The activities underlying Grant A, i.e. the skills facilitator and plan, act as a gatekeeper to the Grant B implementation activities. If planning is not done then $y_{1}=0$ and no utility from any of the grants is possible.

2. In its role as gatekeeper, the profitability of planning is inextricably linked to that of implementation. If firms wish to implement EPT, they first have to do planning, and if planning is unprofitable on its own then the profitability from implementation must 'cover' the loss from planning (Equation). Grant A planning activities may therefore act as a 'bottleneck' in the process, an assertion that will be examined below in the following section.

This analysis changes very little if we add the reality that implementation is not all-or-nothing, but rather can be implemented in increments. Then we merely adjust the grant and cost variables by a proportion indicating the extent to which the workplace skills plan was implemented. However this assumes linearity in the returns and costs, which may also be untrue. The issue of Grant A being a potential bottleneck in the process is dealt with next.

\subsection{Bottlenecks in participation}

The above analyses allow for various permutations in the cost-benefit landscape for firms, including the possibility that they will incur losses for initial participation actions but recoup those losses in later participation. However, such a situation potentially creates a bottleneck in the process, presenting risk elements for firms and possibly repelling them from participating. The possibility that Grant A will act as a bottleneck is particularly related to two conditions, namely firm size and uncertainty.

\section{Organisation size}

It is very likely that firm size will affect the extent to which organisations are likely to pass through the strictures of registering Grant A, to go on to implementing new training. This can be seen by disaggregating the grant and transaction cost amounts. Let the wage bill of the firm be denoted as $W$, and the proportion of wage bill paid for Grants A and B respectively be $G_{a}$ and $G_{b}$ 
respectively. Then the monetary amount paid to the firm for Grant A is $G_{a} W$. Therefore the grant amount for any given organisation is directly proportional to the size of the wage bill, and the marginal benefit of size is constant (equal to $\left.G_{a}\right)$.

However, there is strong reason to believe that the transaction costs associated with any given level of training activities are subject to scales of economy as firm size increases (Middelton et al., 1993). Larger firms are better able to leverage the benefits of a skills development structure to maximum use, already have training infrastructures that can be adapted, have more chance of slack human resources to send on training, and have broad structural capabilities (e.g. knowledge management) that better enables activities such as grant reclamation. Scales of economy also apply in the case of transaction costs associated with the bureaucracy surrounding the grant reclamation: the administrative capabilities of larger firms will more easily absorb these tasks. Therefore if transaction costs are also a function of wage bill, such that $T C=f(W)$, then $f^{\prime}<0$. For the sake of simplicity let the transaction costs be a negative linear function of wage bill, i.e. $T C=-a W$. Then as wage bill size increases the marginal utility of the grant is $G_{a}+a$, which is positive. This is in addition to the likelihood that training itself has a similar result.

Of course, if the grant is big enough, the overall result may well be positive for any firm regardless of size, with larger firms merely being more profitable visà-vis grant reclamation. However it is questioned here whether this is the case. Micro firms in South Africa are those with five to ten workers, and small firms those with ten to fifty employees. While wage bill size will depend on the nature of the business, assuming average wages of R100 000 per worker places a firm with as many as 50 employees with a wage bill of R5 million. Grant A for even this wage bill only garners R11 250 (15 per cent of 1.5 per cent of R5 million). For such a firm, will the costs of setting up a workplace skills plan and engaging a facilitator be greater than this figure? Possibly not - surely the transaction costs of having to prepare formal training reports will be larger. Even smaller organisations will presumably fare worse.

It is therefore argued that the amount for the planning grant may present a loss for many small and perhaps even medium companies. As stated previously, this does not mean that these companies will not do these activities or register for the grant. Many of them may already have doing the activities, and simply not register for the grant, others may find that the benefits from Grant B will make the loss on Grant A activities worthwhile. However, as stated previously, the Grant A requirements present a bottleneck in these cases. A big enough loss on Grant A will deter some firms from even entering into the activities at all, even if the grants where indicating a moderate profit on the implementation activities. 
Policy makers should consider the implications of deterring firms on the margin of participation.

\section{Uncertainty}

Decision making for the Grant A activities occurs at the beginning of the year period stipulated by the legislation. Grant B and other implementation activities then occur later. Future considerations, naturally the roles of uncertainty and potentiality, may play a role in several ways:

- $\quad$ Even in a given year, the returns from the implementation of training are subject to uncertainty and a certain amount of discounting (especially the productivity returns, which as well covered by human capital theory are received far into the future). Companies cannot be sure that they will be able to implement the training for which they plan at the beginning of the year, do not see the fruits of that labour immediately, and have to trust that accreditation of the training and acceptance for grants by the SETAs will go according to plan. Uncertainty regarding these and other elements may cause firms to discount the possibility of returns from implementation. This implicitly means that, notwithstanding its relative certainty, firms may hesitate before entering even Grant A.

- Balancing this, however, is the possibility that the implementation of Grant A activities may have utility past the current year. This assumes of course that the skills development system remains unchanged. If it does, then the initiation of Grant A activities will likely set a platform for future years (i.e. the plans drawn up from scratch in the first year can serve as a template for the following year, etc.) Therefore one can also see the decision to implement a facilitator and plan as applying to several periods. The 'learning curve' effect will almost certainly reduce transaction costs over time.

Therefore managers' perspectives of implementation may include a discounting of both the costs of planning and the benefits of implementation. The latter reinforces the possibility that Grant A is a bottleneck to participation, the former loosens this assumption.

\subsection{The externalities of employer provided training}

One of the benefits of participation not mentioned to date is that of the positive externalities of training. It is well established that, in performing EPT, organisations do not only benefit themselves but also their industries and economies. As the skills level of the workforce rises, so the quality of labour available to all improves. 
Accordingly, it would seem that the greater the extent to which firms understand the externalities, the higher will be their marginal revenue curves and the greater the chance of participation. However it is possible, or even likely, that a circular argument exists here. One of the primary reasons given in the literature for legislating the financing of training is that firms do not understand or appreciate the externalities of training (Middleton et al., 1993). Since this is a rationale for the scheme, it can then hardly be claimed that organisations will buy into the system because of externalities that they were assumed not to appreciate in the first place. More is said on this below.

\subsection{Non-monetary considerations}

A final set of considerations is the effect of non-monetary gains or losses for organisations from the levy grant system. First we must look to political economy considerations, such as networking and reputation effects. Certain organisations may find that participation could act as a 'reputational good', specifically through the facilitation and maintenance of good relations with the policy makers behind the system (notably government) as well as maintenance of a good corporate image (e.g. Etzioni, 1988). Such instrumental ethical considerations would increase the benefits of grant application, making participation more likely. Large corporations, government departments, parastatal organisations, organisations reliant on tenders or other entities partly dependent upon political economic considerations would be the most likely to add these issues into consideration.

Secondly, in line with conventional human capital theory, firms may perceive (often wrongly) that in participating in skills development, notably general development, they are "training people out the door", thus increasing turnover and incurring consequent costs (the "poaching illusion", Middleton, et al., 1993). This problem exists especially under conditions of imperfectly competitive markets (Dougherty \& Tan, 1997). Such a perception, notwithstanding its potentially spurious nature, will drive up manager's perceived costs while decreasing perceived marginal benefit, thus impairing participation.

Finally, this analysis has assumed that firms will know when training increases their monetary utility through increased productivity. However the fact that many firms currently do little training indicates that this is not the case. Is this because training genuinely does not add value in these firms, or because managers are ignorant of the benefits (e.g. Middleton et al., 1993)? In the former case, the productivity improvement term will be zero in actuality, lowering the assumed marginal benefit and making participation less likely. In the latter case, an information problem, it could be assumed that if firms were 
constrained from perceiving the value of extra training before, they may still be so constrained, in which case utility will still be perceived as zero and participation decisions made accordingly. A legislated skills development program may have the extra benefit then of forcing information gathering which would bring the previously hidden benefits of extra training to light (the VET structure itself may serve as an "information clearing house", thus lowering information search costs, Dougherty \& Tan, 1997).

\section{MANAGERIAL AND POLICY IMPLICATIONS}

Obviously this simple model is only an initial glimpse into the complexity of the participation decision for firms. Much could be done to enrich and expand the model, however the preliminary implications here are nonetheless quite important.

The implications for managers arising out of this analysis are fairly simple. Rational organisations are those that will actively seek to maximise their own outcomes. Organisations should be aware of the potential benefits from training under such a system, namely the possibility that extra training will indeed add to their productivity, the benefit of reclaiming a portion of their levy relative to costs, the potential political economic benefits (especially networking and reputation effects), etc. Of course, managers will be concerned with costs, including direct and transaction costs, as well as the effect of training on turnover and wages. Managers would assumedly prefer a grant system whereby they could set their own level of participation, thus optimising utility. In addition, firms may prefer that the maximum possible amount of training is firm-specific, thus avoiding increased turnover.

From a policy point of view, the analysis is more problematic. Notwithstanding the preferences of organisations, legislators have many stakeholders outside of organisations. The policy implications of this analysis are thus wider. Firstly, it is clear that if policy makers are concerned about participation, they should ensure that the levy-grant system minimises transaction costs for organisations. This is a question of efficiency, and SETA's appear to be undertaking this task.

Secondly, 'bottlenecks' in the participation rate should be carefully considered. Currently in South Africa, it appears as if many organisations will have little incentive to stop at Grant A: they will either not participate or will implement some training. While this may be desirable, it also may reduce the numbers of firms that participate at all. Whether the strategic aspects of the framework (planning activities) are less desirable than the training implementation (Grants $\mathrm{B} \& \mathrm{C}$ activities) is a policy issue however. 
Thirdly, policy makers should be very aware of firm size effects. Larger firms will inherently find it easier to participate based on multiple rationales. These include economies of scale in training structures (making current training structures and budgets more likely and transaction costs lower), a lower opportunity cost of capital, the higher likelihood of political benefits of participation etc. The suggestion that small firms be excluded is therefore given further impetus (Ziderman, 2001).

The type of training encouraged should also be considered. Organisations would prefer training that they perceive as (1) high-utility and (2) specific to their organisation. They will make their participation decisions based on these types of internal considerations. However policy makers may prefer socially useful training that organisations might not perceive as high-utility. Either the organisations are wrong about the utility (in which case they should be educated) or the grant system should balance the need for socially valuable training with organisationally desired training to cater for desired participation rates.

Ultimately it is hoped that policy makers will be better equipped to understand the real impact of their legislation, and researchers will be able to establish whether firm participation can and should be a central rationale behind levyrebate systems.

\section{REFERENCES}

1 DOUGHERTY, C. (1989) "The cost-effectiveness of national training systems in developing nations”, World Bank Working Paper WPS 171.

2 DOUGHERTY, C. \& TAN, J.P. (1997) "Financing training: issues and options”, International Journal of Manpower, 18 (1): 29-62.

3 DUCCI, M.A. (1997) "New challenges to vocational training authorities: lessons from the Latin American experience", International Journal of Manpower, 18 (1): 160-184.

4 ETZIONI, A. (1988) The Moral Dimension: Towards a New Economics, Free Press: New York.

5 GLASSKOV, V. (ed.) (1994) Alternative Schemes of Financing Training, International Labour Office: Geneva.

6 GRAWITZKY, R. (2002) "Is business committed to skills development?”, South African Labour Bulletin, 26 (2): 37-38.

7 GREIG, F. (1997) "Enterprise training”, International Journal of Manpower, 18 (1): 185-205. 
8 LEE, G.J. (2003). "Reviewing the economics of the skills development levy: A political non-sequitur?”, South African Journal of Labour Relations, 26 (1): 4-20.

9 LEE, G.J. (2001) “Training utility and levy-grant incentives”, Journal of Human Resource Costing \& Accounting, 7 (1/2): 41-52.

10 MIDDLETON, J., ZIDERMAN, A. \& VAN ADAMS, A. (1993) Skills for Productivity: Vocational Education and Training in Developing Countries, Oxford University Press.

11 South African Funding Mechanism Research. (1997) National Training Board, Phase 1, Study 2.

12 VERDIER, E. (1994) “Training and enterprise in France”, International Journal of Manpower, 15 (5): 38-54.

13 WHALLEY, J. \& ZIDERMAN, A. (1990) "Financing training in developing countries: the role of payroll taxes", Economics of Education Review, 9 (4): 377-87.

14 ZIDERMAN, A. (1996) "Payroll levies” In A.C. Tuijnman (ed.) International Encyclopedia of Adult Education and Training, Elsevier Science: 313-18.

15 ZIDERMAN, A. (2001) "Financing vocational training to meet policy objectives: Sub-Saharan Africa”, Report prepared for World Bank, August revision. 